\title{
Preliminary Study on the Prioritization of Asset Integrity Elements for Catastrophic Industrial Accident's Warning Signs Using Analytic Hierarchy Process (AHP)
}

\author{
Siti Hawa Amrana, Azizan Ramli*,b, Nurul Sa'aadah Sulaimana \\ aFaculty of Chemical and Process Engineering Technology, College of Engineering Technology, Universiti Malaysia Pahang, Lebuhraya Tun Abdul \\ Razak, 26300 Gambang,Kuantan, Pahang, Malaysia \\ bFaculty of Industrial Sciences and Technology, College of Computing and Applied Sciences, Universiti Malaysia Pahang, Lebuhraya Tun Abdul \\ Razak, 26300 Gambang,Kuantan, Pahang, Malaysia
}

\begin{abstract}
The catastrophic incident is a big event with high level of consequences and it is defined as either natural or man-made. Therefore, in appreciating the importance of disaster management cycle of the preparedness phase, recognizing the warning signs is one of the considerable means to avoid huge losses in term of property damage and human life. Thus, this study is to emphasize on asset integrity elements based on the "Incident Warning Sign SelfAssessment Tool" of the Center for Chemical Process Safety (CCPS-AIChE). The aim is to conduct the preliminary study on prioritizing the importance level of these elements and determine the weightage of each. A set of questions was constructed and distributed to the safety experts from the selected process industries located at East Coast region of West Malaysia. The Analytic Hierarchy Process (AHP) is used as a response analysis tool. The relevant data were derived using pairwise comparison analysis. The findings show that the weightage for "alarm \& safety system" $(0.219)$ and "maintenance' $(0.212)$ are at the highest priority amongst other clusters. The finding indicates that these two factors ought to be at the apex of the mitigations and preparedness measures which require an immediate attention.
\end{abstract}

\section{KEYWORDS}

Analytic hierarchy process,

warning signs,

expert judgement.

\section{INTRODUCTION}

Catastrophic incident is a big event with high level consequences while an incident is any unplanned event that can happen either with or without consequences. Its effects are subject to magnitude and the vulnerability of the surroundings. There are two types of catastrophes that are anthropogenic or man-made ("Act of Man") and natural ("Act of Nature"). Catastrophe will cause tremendous impacts to the environment, population, economy and infrastructure. It also can cause serious injuries and even death. However, the purpose of this paper is to discuss about catastrophic incidents caused by technological hazards. Therefore, the word "catastrophe" in this paper is referring to the man-made incidents. Thing has to be corrected now, and there is an urgent need to wake everybody up before our industrialization process turn into devastating event. The catastrophic incidents are actually incidents with substantial consequences that expand from fewer consequential incidents. Therefore, if the response is delayed until the series of incidents increase, indeed, it may be too late to take an efficient action. Big-scale companies are revealed to risks not only the safety of their workers and surrounding, but also can give a big impact to their business (Barrault et al., 2012). Catastrophic incidents actually do not just happen. In term of catastrophic incidents caused by technological hazards, it will occur when there are human mistakes or an error or weakness in the management system associated with the process. Moreover, dealing with humanmachine system is seen as a complex interaction whereby it is essential to think about how the system malfunction and causes an accident (Marhavalis et al., 2011). Thus, prior identification of an inadequacy of the control system or system malfunction emerges as an effective and proactive measures to prevent industrial catastrophe. For example, the release of harmful materials is one of the reasons why catastrophic incidents happen. This happens as a result of diversion process from the ordinary conducting conditions (Barontini et al., 2008). The need to recognise any warning signs before the incidents happen is essential and unluckily, in certain cases, these signs appear in short period of time. Thus, when a warning sign was noticed, it is necessary for us to take an immediate action. The organization must take an action and identify the management system weaknesses until precautionary actions are in order.

The most horrifying industrial catastrophe or disaster in modern history- deadly explosion and the release of methyl isocyanate from pesticide plant which claimed thousands of life in Bhopal, India (known as Bhopal Disaster, 1984). This explosion not only caused an instantaneous death of the victims but leaving the survived victims with multiple health effects, even up to their tertiary generation. Another example is reactor meltdown at the Chernobyl nuclear plant in 1986 which killed and left thousands of victims with radioactive-caused diseases. Beside these two classic examples, industrial community has been shocked by warehouse explosion in the port city of Tianjin, China (occurred in 2015) which claimed 
huge loss of properties and life. This tragedy is the latest in a long and bloody history of industrial disasters which requires immediate attention from all. These are amongst the many of the examples which indicate that sometimes the impacts caused by man-made disasters are no less damaging than the natural catastrophes. Floods, hurricanes, tsunami and all kinds of natural disasters, in certain circumstances, are obviously causing mass casualties, huge loss of properties and asking for millions dollars of assistance for rehabilitation and recovery processes. However, the rare-to-happen technology-induced catastrophe such as chemical plants explosion and release of the hazardous materials also able to cause long-term impacts to life and environment. The aforesaid two classic examples are revealing an evidence to this argument. The Bhopal disaster as well as the Chernobyl disaster are leaving us with uncounted tearing-stories from the victims and their relatives until to date. Moreover, Britkov and Sergeev (1998) argued that technological accidents with destructive consequence do happen from time to time. Therefore, due to escalating introduction of advanced technologies which resulted from research and development, the emergence of concurrent safety measures by all means cannot be in isolation.

The hazard can be detected visually or by the use of specific equipment. Usually physical hazards are more noticeable than the chemical ones. If systemic weaknesses can't be detected, it can be far more significant. However, some people don't know what the warning sign is, how they can notice when it happens and why it is closely related to catastrophic incidents. Before an incident occurs, warning sign will appear first to "inform' the possibility of an impending catastrophe to emerge. We must know what kind of warning signs that will lead to incident and must act properly to avoid the occurrence. The organizations should focus more on avoiding catastrophic incidents rather than trying to take an action on incidents that can cause consequences. But, it is more important to detect the warning signs first before proceed with the next step of preventing disasters from happening.

According to Jakiul and Faisal (2012), most of incident cases in process facilities are due to poor asset integrity systems and the negligence of asset integrity assurance. Thus, serious losses can't be avoided if issue of system integrity not being taken seriously from the design stage to operation and maintenance. This means that equipment should also works as a protector or preventer against loss of containment and not only as a tool of operation. According to Kusumawardhani and Markeset (2015), the asset integrity is manageable through proper inspection and testing as well as maintenance. Precautionary action is also necessary when the equipment has passed its service life and ageing. Therefore, it is imperative to identify the critical elements relating to asset integrity and probability of early detection to deter malfunction which will ultimately trigger the unprecedented event of catastrophe. Thing has to be corrected now, and there is an urgent need to wake everybody up before our industrialization process turn into devastating event.

Thus, the aim of this study is to determine the weightage of key elements to expand a rating system for catastrophic incident warning signs on asset integrity. The elements which are derived from the "Incident Warning Sign SelfAssessment Tool" of the Center for Chemical Process Safety (CCPS-AlChE) and expert survey will have either direct or indirect effects on the asset integrity warning sign. However, we would like to stress here that the findings from this study is the consensus judgement amongst small group of safety experts at the East Coast region of Peninsular Malaysia which comprised of three states (Pahang, Kelantan and Terengganu). The result is based on their viewpoints towards the issues pertaining to asset integrity matter on how they gauge the priority level of those related elements.

\section{MATERIALS AND METHODS}

\section{Construction of the questionnaire}

The questionnaire related to asset integrity which has been adopted from Center for Chemical Process Safety (CCPSAiChE) was reconstructed and clustered (CCPS-AiChE, 2012) in order to ease the process of assessment by the safety experts. Clustering of factors will guide the experts to response and judge in a systematic way. There are nine types of warning signs as stated in CCPS's "Incident Warning Sign Self-Assessment Tool". However, for the purpose of this study, only asset integrity was chosen and it has been clustered into five categories consist of operation, alarm \& safety system, organizational structure, maintenance and equipment. For each category, they have their own elements to represent the types of their importance. Figure 1 shows the Analytic Hierarchy Process (AHP) hierarchical structure for the asset integrity elements. Prior to this process, an open-ended survey was conducted to gain general information about the issue and practices related to asset integrity management. There were eight companies involved in this study. The findings from this open-ended survey were then used and complemented the next stage of AHP process. 


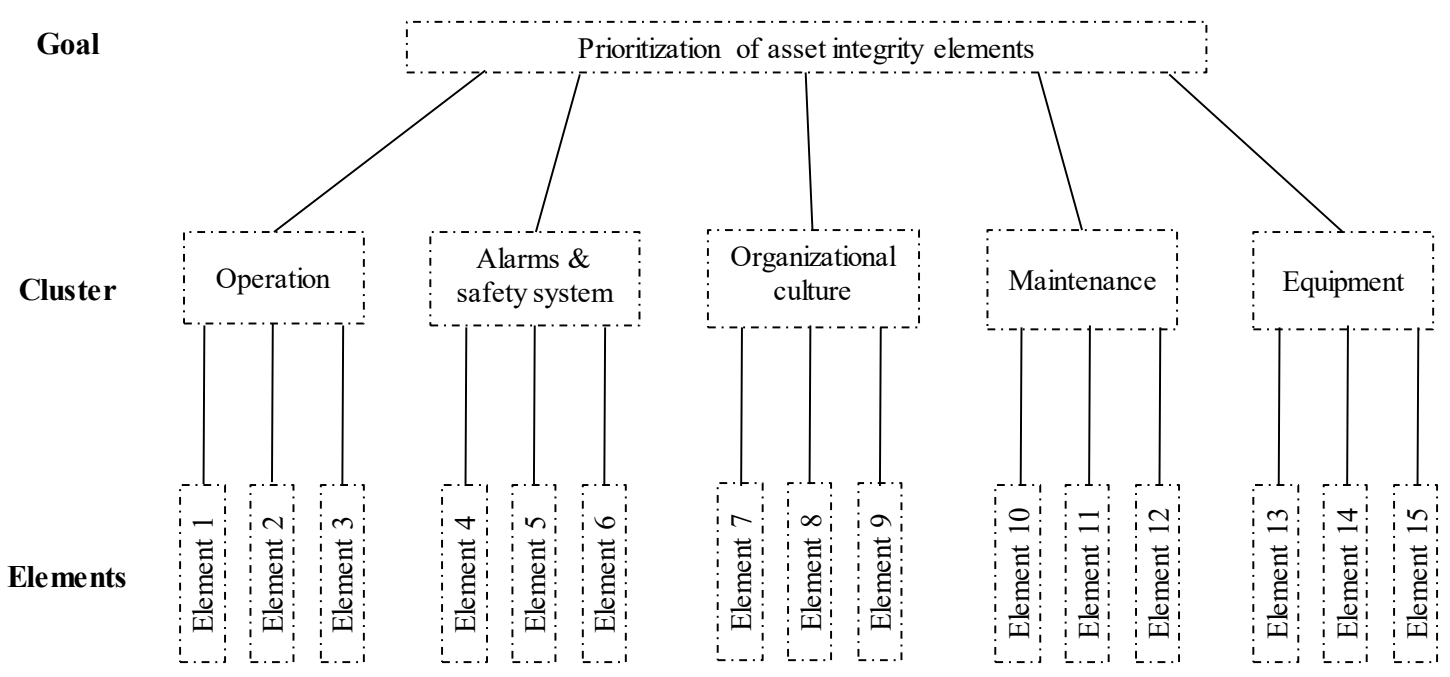

Figure. 1: AHP evaluation hierarchical structure in the process of prioritizing criteria for the asset integrity

\section{Distribution of the questionnaires to the safety experts}

The constructed questionnaire were distributed to the safety experts from diverse companies, range from governmentlinked companies (GLC) to the multi-national companies (MNC). All the selected companies are under category of highrisk industries and they are producing chemicals and petrochemical-based products. The questionnaire were sent to the respective personnel via email. The time given to all respondents to fill up the survey form is about two weeks.

\section{Selection of Analytic Hierarchy Process (AHP's) experts}

The Analytic Hierarchy Process or AHP is a mathematical method which uses Saaty scale to determine the level of priority and usually based on an opinion of the group of experts. AHP is a multi-criteria decision making (MCDM) method consists of four main steps: 1) modelling the problem, 2) valuing the weights, 3) aggregating the weights, and 4) analysis of sensitivity (Ishizaka \& Labib, 2011). Furthermore, AHP's evaluation method requires a small number of main variables which together explain many variants in the warning sign. Each element should be weighted relatively to determine the level of importance of each warning sign. According to Kil et al. (2015), the minimum number of expertise that usually used for AHP is five people. However, the "number of expert" is not more important than the level of their expertise and experience in their respective field. Selection of the experts is based on their seniority and involvement in process safety management.Thus, in this research, eight experts with an average experience in process safety management (PSM) more than ten years are involved.

\section{Pairwise comparisons}

The relative importance of the criterions can be determined by using pairwise comparison. The performance of the option regarding to the considered criterion will be better if it can achieve a high score. According to Evangelos and Stuart (1995), to quantify correctly is an important step in the decision-making process of various criteria that uses qualitative data. There are no units in pairwise comparison. The pairwise comparisons are used to define the similarity or difference of warning sign level. For example, suppose that warning A is better than warning B. After that, when warning A is compare to warning $\mathrm{B}$, then the respondent has to determine that warning $\mathrm{A}$ is more important than warning $\mathrm{B}$ by selecting the appropriate scale (1 to 9). A scale of ranking importance based on a pairwise comparison of questionnaires is as shown in Table 1. This survey consists of comparing a pair of individual element on the same hierarchy within elements group. For each element, it has a brief description to explain the content.

Table 1. Saaty scale

\begin{tabular}{ccl}
\hline Rank & Importance & Explanation \\
\hline $\mathbf{1}$ & Equally important & Two variables equal to the objective \\
\hline $\mathbf{3}$ & Moderately important & Moderate importance of one over another \\
\hline $\mathbf{5}$ & Strongly important & Experience and judgement strongly favour one over the other \\
\hline $\mathbf{9}$ & Very strong important & Criterion is strongly favoured and its dominance is demonstrated in practice \\
\hline $\mathbf{2 , 4 , 6 , 8}$ & Absolutely important & Importance of one over another affirmed on the highest possible order \\
& $\begin{array}{c}\text { Intermediate preferences } \\
\text { between adjacent scales }\end{array}$ & When compromise in needed \\
\hline
\end{tabular}

Source: (Ali et al., 2012; Ezatollah, 2006; Pedcris et al., 2013; Shi et al., 2012) 


\section{RESULTS AND DISCUSSIONS}

\section{Feedback from experts}

The result of an open-ended survey was summarised and tabulated in Table 2.

Table 2. Aggregated result from open-ended survey on asset integrity management

\begin{tabular}{|c|c|}
\hline $\begin{array}{l}\text { Questions } \\
\text { Source: modified from asset integrity element of "Incident Warning Sign } \\
\text { Self-Assessment Tool" of the Center for Chemical Process Safety: CCPS- } \\
\text { AIChE (2012). }\end{array}$ & Summary of the answer/responses \\
\hline $\begin{array}{l}\text { Is operation continue when safeguards are known to be } \\
\text { impaired? }\end{array}$ & $\begin{array}{l}\text { All respondents have answered "NO". } \\
\text { It is clearly understood that company should strictly follow Asset } \\
\text { Integrity Program (preventive maintenance) }\end{array}$ \\
\hline Inspections of an overdue equipment & Being practiced and company policy is very strict \\
\hline Postponement of relief valve testing. & $\begin{array}{l}\text { All respondents have answered "NO". } \\
\text { It is clearly understood that company should strictly follow Asset } \\
\text { Integrity Program (preventive maintenance) }\end{array}$ \\
\hline Formal maintenance program is not a common practice. & $\begin{array}{l}\text { All respondents have answered "NO". } \\
\text { It is clearly understood that company should strictly follow Asset } \\
\text { Integrity Program (preventive maintenance) }\end{array}$ \\
\hline A "run-to-failure" philosophy is a common practice & All respondents have answered "NO". \\
\hline $\begin{array}{l}\text { Budget is the main concern and the maintenance deferment } \\
\text { is allowed until next cycle }\end{array}$ & All respondents have answered "NO". \\
\hline $\begin{array}{l}\text { Cost reduction is the priority and it was accepted to reduce the } \\
\text { preventive maintenance activities (to save money) }\end{array}$ & All respondents have answered "NO". \\
\hline $\begin{array}{l}\text { No practice of tagging of the broken or defective equipment } \\
\text { and still in service }\end{array}$ & $\begin{array}{l}\text { It is not a practice. Will not happen because company policy is } \\
\text { strict }\end{array}$ \\
\hline Mechanical failures repetitively occur & All respondents have answered "NO". \\
\hline An evidence of corrosion and equipment deterioration & $\begin{array}{l}\text { Regular inspection and equipment monitoring are a common } \\
\text { practice. Immediate actions will be taken because company policy } \\
\text { is strict }\end{array}$ \\
\hline Trips and nuisance alarms & Because of high pressure, interlock system \\
\hline Leaks occur at a high frequency & Closely monitored and PSM programs always in place \\
\hline $\begin{array}{l}\text { Good engineering practices are not in place while installing } \\
\text { equipment and hardware }\end{array}$ & Cannot happen because company policy is strict \\
\hline Accepts the improper application of equipment and hardware & Cannot happen because company policy is strict \\
\hline Bypassed alarms and safety systems & Because of alarm management program, interlock system \\
\hline Use facility firewater to cool process equipment & Not allowed and not necessary \\
\hline Lack of alarms and instrument management & All respondents have answered "NO", it is under PM program \\
\hline $\begin{array}{l}\text { Out-of-service safety instrumented system is still used to } \\
\text { operate the process and risk assessment or management of } \\
\text { change is not implemented. }\end{array}$ & Not allowed and PSM is in place \\
\hline $\begin{array}{l}\text { No testing being carried out to critical safety system or it is not } \\
\text { functional properly }\end{array}$ & Not allowed. Alarm management program \\
\hline Inadequate practices for establishing equipment critically & Cannot happen because company policy is strict \\
\hline Working on equipment that is in service & Cannot happen because company policy is strict \\
\hline Temporary or substandard repairs are prevalent & All respondents have answered "NO". \\
\hline No periodic preventive maintenance implemented & Not allowed. Poor management \\
\hline No up-to-date repair record of the equipment & Cannot happen because company policy is strict \\
\hline Chronic problems with the maintenance planning system & All respondents have answered "NO". \\
\hline $\begin{array}{l}\text { Management of equipment deficiencies without formal } \\
\text { process }\end{array}$ & Cannot happen because company policy is strict \\
\hline Maintenance activities are inadequately closed out & $\begin{array}{l}\text { Poor management but cannot happen because company } \\
\text { policy is strict }\end{array}$ \\
\hline
\end{tabular}

Initially, it is well understood that all the respondents (company) have followed a very strict internal regulation with regards to preventive maintenance (PM) activity. This was translated into the practice of precautionary actions pertaining to asset integrity matters such as inspection, testing, monitoring as well as fixed budgeting (financial supports). For example, it is clearly mentioned when the respondent stated that the operation will not be executed in the absence of regular PM and in the existence of abnormalities of the equipment. In other word, the practice of process safety management (PSM) always in place, especially when it comes to the issue related to asset integrity. 


\section{Tendencies for weighted factors}

The AHP questions were developed based on the findings of open-ended survey and CCPS self-assessment tool. The selected safety experts were then contacted and engaged with pairwise comparison assessment. The findings were analysed and presented in the tabular form as shown in Table 3. The geometric mean for the weightage of each element was calculated based on the weightage assessed by the group of experts. The weightage scale used is based on Table 1 .

By comparing the mean weights of each cluster, the weightage of "alarm \& safety system" (0.219) and "maintenance" (0.212) showed very significant levels of importance. This result showed that the matter related to alarm and safety system, and maintenance are standing at the most priority as far as asset integrity is concern. The respondents also agreed that these two factors (in this case; "cluster") ought to be treated in prior to the rest of the factors (clusters). However, amongst the elements of all clusters, the weightage for "even safeguards are impaired, operation still continue" (0.649) indicated the highest importance (under the cluster of “operation"). This shows that the issue of safeguards can't be compromised. For whatever reasons, if there is an abnormality detected within the existing safety barriers, the operations shouldn't be continued until proper actions are in place. As for the cluster of "alarm \& safety system", the highest level of importance is "No testing being carried out to critical safety system or it is not functional properly" $(0.377)$. The element related to "Mechanical failures repetitively occur" (0.446) is the scorer in term of priority for "organizational culture's" cluster. Meanwhile, "chronic problem with the maintenance planning system" (0.175) was selected as the most importance element under "maintenance" category. The element of "No practice of tagging of the broken or defective equipment and still in service" (0.185) indicated relatively higher weightage amongst elements in the "equipment" category.

Table 3. Geometric Mean of Weighted Elements

\begin{tabular}{|c|c|c|c|}
\hline Clusters & Mean Weight & $\begin{array}{l}\text { Elements } \\
\text { Source: modified from asset integrity element of "Incident Warning } \\
\text { Sign Self-Assessment Tool" of the Center for Chemical Process } \\
\text { Safety: CCPS-AIChE (2012). }\end{array}$ & Mean Weight \\
\hline \multirow[b]{3}{*}{ Operation } & \multirow[b]{3}{*}{0.165} & Even safeguards are impaired, operation still continue & 0.649 \\
\hline & & Postponement of relief valve testing. & 0.208 \\
\hline & & $\begin{array}{l}\text { Out-of-service safety instrumented system is still used to } \\
\text { operate the process and risk assessment or management of } \\
\text { change is not implemented. }\end{array}$ & 0.142 \\
\hline \multirow{5}{*}{$\begin{array}{l}\text { Alarm \& Safety } \\
\text { System }\end{array}$} & \multirow{5}{*}{0.219} & Lack of alarms and instrument management & 0.187 \\
\hline & & Bypassed alarms and safety systems & 0.201 \\
\hline & & $\begin{array}{l}\text { No testing being carried out to critical safety system or it is not } \\
\text { functional properly }\end{array}$ & 0.377 \\
\hline & & Trips and nuisance alarms & 0.119 \\
\hline & & Use facility firewater to cool process equipment & 0.113 \\
\hline \multirow{3}{*}{$\begin{array}{l}\text { Organizational } \\
\text { Culture }\end{array}$} & \multirow{3}{*}{0.201} & Mechanical failures repetitively occur & 0.446 \\
\hline & & Leaks occur at a high frequency & 0.312 \\
\hline & & A "run-to-failure" philosophy is a common practice & 0.241 \\
\hline \multirow{7}{*}{ Maintenance } & \multirow{7}{*}{0.212} & $\begin{array}{l}\text { Budget is the main concern and the maintenance deferment is } \\
\text { allowed until next cycle }\end{array}$ & 0.140 \\
\hline & & $\begin{array}{l}\text { Cost reduction is the priority and it was accepted to reduce the } \\
\text { preventive maintenance activities (to save money) }\end{array}$ & 0.117 \\
\hline & & Maintenance activities are inadequately closed out & 0.116 \\
\hline & & Chronic problems with the maintenance planning system & 0.175 \\
\hline & & No periodic preventive maintenance implemented & 0.163 \\
\hline & & Formal maintenance program is not a common practice. & 0.147 \\
\hline & & Temporary or substandard repairs are prevalent & 0.138 \\
\hline \multirow{9}{*}{ Equipment } & \multirow{9}{*}{0.202} & Inspections of an overdue equipment & 0.150 \\
\hline & & $\begin{array}{l}\text { No practice of tagging of the broken or defective equipment } \\
\text { and still in service }\end{array}$ & 0.185 \\
\hline & & Accepts the improper application of equipment and hardware & 0.096 \\
\hline & & $\begin{array}{l}\text { Good engineering practices are not in place while installing } \\
\text { equipment and hardware }\end{array}$ & 0.109 \\
\hline & & Working on equipment that is in service & 0.119 \\
\hline & & No up-to-date repair record of the equipment & 0.086 \\
\hline & & $\begin{array}{l}\text { Management of equipment deficiencies without formal } \\
\text { process }\end{array}$ & 0.081 \\
\hline & & An evidence of corrosion and equipment deterioration & 0.088 \\
\hline & & Inadequate practices for establishing equipment criticality & 0.081 \\
\hline
\end{tabular}




\section{CONCLUSIONS}

Sometimes the catastrophic impacts caused by anthropogenic activities are no less damaging than the natural acts. One of the main concerns in process safety management is the integrity of the equipment. The organizational inability to identify the early warnings signs of the critical assets might cause an untoward incident. Thus, this study is to prioritize the importance elements of asset integrity based on "Incident Warning Sign Self-Assessment Tool", Center for Chemical Process Safety (CCPS-AiChE) from the viewpoint of group of safety experts in the East Coast region of Peninsular Malaysia. To obtain the aggregated expert judgement, AHP method was used. AHP provides a robust method for prioritization of the identified elements. This method can guide the safety and health department to create a realistic risk management for asset integrity through determination of elements in priority. In term of clusters prioritization, the weightage scores of "alarm \& safety system" $(0.219)$ and "maintenance" $(0.212)$ are at the apex of importance's pyramid. However, amongst the elements, the issue of safeguards stands at the first priority. For whatever reasons, if there is an abnormality detected within the existing safety barriers, the operations shouldn't be continued until proper actions are in place.

\section{ACKNOWLEDGMENT}

The authors gratitude goes to the Faculty of Chemical and Process Engineering Technology for their support. Our special thanks to all the industrial safety experts who have involved in the survey and interview session.

\section{REFERENCES}

Ali, G., Kerem, T., Korkmaz, U. (2012). Application of Combined SWOT and AHP: A Case Study for a Manufacturing Firm. Procedia - Social and Behavioral Sciences, 58, $1525-1534$.

Barontini, F., Zanelli, S., Cozzani, V., Gigante, L., Lunghi, A., Rota, R., Cardillo, P. (2008). Experimental strategies for the identification of substances formed in the loss of control of chemical industrial processes. Loss Prevention in the Process Industries, 21(4), 407-422.

Barrault, S., Marzal, H., Chevalier, F. (2012). Risk Management of Major Industrial Complex Site: Key Success FactorOCP Example. Procedia Engineering, 46, 285-287.

Britkov, V., Sergeev, G. (1998). Risk management: role of social factors in major industrial accidents. Safety Science, 30 , $173-181$

Center for chemical process safety of the American Institute of Chemical Engineers (2012). Recognizing catastrophic incident warning signs in the process industries. New Jersey: John Wiley \& Sons

Evangelos, T., Stuart, H.M. (1995). Using the Analytic Hierarchy Process for Decision Making in Engineering Applications: Some Challenges. Inter Journal of Industrial Engineering: Applications and Practice, 2(1), 35-44.

Ezatollah, K. (2006). Appropriateness of farmers? adoption of irrigation methods: The application of the AHP model. Agricultural Systems, 87, 101-119.

Ishizaka, A., Labib, A. (2011). Review of the main developments in the analytic hierarchy process. Expert Systems with Applications, 38, 14336-14345.

Jakiul, H., Faisal, K. (2012). Risk-based asset integrity indicators. Journal of Loss Prevention in the Process Industries, $25,544-554$.

Kil, S.H., Lee, D.K., Kim, J.H., Li, M.H., Newman, G. (2015). Utilizing the Analytic Hierarchy Process to Establish Weighted Values for Evaluating the Stability of Slope Revegetation based on Hydroseeding Applications in South Korea. Sustainability, 1-17.

Kusumawardhani, M., Markeset, T. (2015). Asset Integrity Knowledge Management: A Case Study from the Petroleum Industry. Operation and Supply Chain Management, 8(3), 146-153.

Marhavalis, P.K., Koulouriotis, D., Gemeni, V. (2011). Risk analysis and assessment methodologies in the work sites: On a review classification and comparartive study of the scientific literature of the period 2000-2009. Journal of Loss Prevention in the Process Industries, 24, 477-523.

Pedcris, M., Orencio, Masahiko, F. A. (2013). localized disaster-resilience index to assess coastal communities based on an analytic hierarchy process (AHP). International Journal of Disaster Risk Reduction, 3, 62-75.

Shi, S., Jiang, M., Liu, Y., Li, R. (2012). Risk assessment on falling from height based on AHP-fuzzy. Procedia Engineering, 45, $112-118$. 